\title{
ARetrospectivestudy of Medication Utilization Pattern and Clinical Outcome in Middle-Aged and Older Patients with Type 2 Diabetes Mellitus in Qatar
}

Navas Nadukkandiyil*, Hanadi Khamis Al Hamad, Noorudeen Kunnummal, Sameer Valappil, Marwan Ramadan, Maryam Al Obaidely, Haroon Saleh, Mansoor Ali, Mahmoud Al Refae, Faizal Umminiyattle, Amin Abdelghany, Fatima Abu Najma, Mona Taweel, Shafi Khan, Armaghan Butt and Essa Al Sulaiti

Department of Geriatric Medicine, Al-Rumailah hospital, Hamad Medical Corporation, Doha, Qatar

*Corresponding author: Navas Nadukkandiyil, Fellow, Department of Geriatric Medicine, Al-Rumailah Hospital, Hamad Medical Corporation, P.O box 3050, Doha, Qatar, Tel:+97444393392; Fax:+9744398111; E-mail: drnavasnk30@gmail.com

Received date: October 08, 2018; Accepted date: November 30, 2018; Published date: December 07, 2018

Copyright: (c) 2018 Nadukkandiyil N, et al. This is an open-access article distributed under the terms of the Creative Commons Attribution License, which permits unrestricted use, distribution, and reproduction in any medium, provided the original author and source are credited.

\begin{abstract}
Background: Type 2 Diabetes Mellitus (DM) is a costly illness and general one related with significant mortality and morbidity. In spite of this, there is only small information on the clinical outcome and 'real-world' medication utilization patterns for middle age and older patients with type-2 diabetes. Therefore, the main aim of the study is to evaluate the Medication Utilization Pattern and Clinical outcome in Type2 DM for middle age and older Patients.

Methods: A retrospective longitudinal study was conducted from 1st Jan 2016 to 30 June 2016 in an out-patient department of a tertiary hospital in Doha, Qatar. The outpatients with Type 2 DM and age above 55 years are included in the study. The sample size for the study is selected 150 middle-aged and older patients from a total of 800 patients who attended Rumailah hospital Geriatric outpatient clinic during the study period. Data were compared to find out the associations between DM and socio-demographic and clinical indicators using inferential statistics. ROC analysis, ANOVA, Chi square test and logistic regression were used for analytical purpose. P-value $<0.05$ was considered to be statistically significant.
\end{abstract}

Results: Results show that combination anti-diabetic therapy was more used than monotherapy. The study found a significant positive correlation between Age and $\mathrm{HbA} 1 \mathrm{C}$ in addition to Fasting Blood Sugar (FBS) and Glycated hemoglobin (HbA1c) levels. Under variable treatment regimens, the majority of 118 older patients were using Metformin as oral hypoglycemic agent; for insulin, the most commonly used treatment regimen is Glargine Insulin; with regards to anti-hypertensive, calcium channel blocker, Amlodipine is the most prescribed medication for patients followed by angiotensin receptor blocker, Valsartan. The use of a combination of Metformin/ Sitagliptin or Vildagliptin shows higher non-insulin anti-diabetic (NIAD) drug prescriptions as per attaining target. ROC analysis showed an elevation in cut off levels of HbAc1 with advance in age. Drug utilization pattern of different age groups showed that $<65$ age group monotherapy was better; 65-74 age group monotherapy and combination therapy was more effective in attaining the target $\mathrm{HbA} 1 \mathrm{c}$. However, drug utilization pattern was comparable in in patients above 75 years.

Conclusion: Drug utilization pattern was different according to age group. Monotherapy was found to be most effective in attaining the target $\mathrm{HbA} 1 \mathrm{c}$ in middle aged and young elderly population. Metformin (78.7\%), Gliclazide(32.7\%), Sitagliptin(27.3\%) and Vildagliptin(17.3\%) were the most predominantly prescribed and consumed antidiabetes medicines. The insulin-based therapies were not effective in all age group to attain better glycemic control compared to oral antidiabetic drugs. Our data suggest that standard treatment guideline was followed properly among diabetic older population in Qatar.

Keywords: Drug utilization pattern; Type 2 Diabetes Mellitus; Older persons; Clinical outcome

\section{Introduction}

There is a gradual increase in aging population with the high encumbrance of chronical conditions either with a single chronic condition or with multiple conditions. Over the past 20 years, there is a high increase found in the prevalence of Diabetes Mellitus (DM) in various regions of the world and presently it is considered a global health issue [1]. In 2012, around 1.5 million people died due to DM, wherein around 80 percent of these deaths were from low and middleincome nations [2]. In 2014, it was estimated that around 8.5 percent of adults [3] were diagnosed with DM globally and presently around
387 million people are prone to Type 2 Diabetes (T2DM), and by the year 2035, the prevalence of T2DM is predicted to increase up to 592 million. Presently, the count of individuals with T2DM is increasing in every nation. Among them, DM is prevalent and is becoming widespread among older people. Certainly, around 25 percent of the population in the world is affected by DM around the age of 65 years [4]. DM is a chronic metabolic disorder virtually affects almost every cell in the body which in turn leads to pathology in multiple organ systems and consequently leading to higher healthcare expenses. DM is the prominent reason for mortality and morbidity; it is also the main reason for numerous macrovascular diseases (coronary artery diseases, peripheral vascular diseases, stroke) and microvascular diseases (retinopathy, neuropathy, and nephropathy). According to a consensus statement by European Association for the Study of Diabetes (EASD) 
Citation: Nadukkandiyil N, Nadukkandiyil HK, Kunnummal NK, Umminiyattle F, Valappil SA, et al. (2018) A retrospective study of Medication Utilization Pattern and Clinical Outcome in Middle-Aged and Older Patients with Type 2 Diabetes Mellitus in Qatar. J Diabetes Metab 9: 815. doi:10.4172/2155-6156.1000815

Page 2 of 11

and American Diabetes Association (ADA), type 2 diabetes is considered as a progressive loss of $\beta$-cell function and a consistent requirement for the progressive and initial accumulation of glucoselowering plans [5]. It is a challenging task for maintaining and achieving glycemic control as the main treatment goal in managing Type 2 DM (T2DM).

The country which is presently experiencing an alarming increase in the prevalence of T2DM is Qatar, a Middle Eastern country and it is part of the Gulf Cooperation Council. Since 1997, Qatar has been a part of the International Diabetes Federation (IDF) and in 2017, Qatar had around 0.24 million cases of T2DM wherein adult population was around 16.52 percent between the age group 20 to 79 years [4], it was projected that at least one in every four adult Qataris will have diabetes by 2050 . These high rates of diabetes in the region have precipitated significant research interest aimed at identifying risk factors that may explain the high diabetes prevalence. A previous study conducted by Bener et al. in Qatar has found a reasonable increase in the prevalence of DM over adult population in Qatari6. A severe glycemic control of $\mathrm{DM}$ is foremost important for reducing the risk of diabetes-related conditions like ischemic heart disease, stroke, and peripheral cardiovascular diseases [6].

Diabetes mellitus (T2DM) is a chronic metabolic a disorder affecting virtually every cell in the body leading to pathology in multiple organ systems with consequent high health care resource expenditures. In the context of Qatar, risk factors associated with diabetes were examined in one study Bener et al. (2009), but there was a lack of investigations related to drug utilization in diabetic adult population. Therefore, the present study is to analyze the effectiveness of the drugs in controlling the glycemic status and to decrease the rate of complications related to diabetes. Hence, the study aims in evaluating the utilization of drugs pattern in geriatric T2DM patients who are at an alarming rate in Qatar. A retrospective longitudinal study is performed in identifying the utilization of combined antidiabetic therapy rather than using monotherapy for achieving optimal glycemic control.

\section{Research Methodology}

\section{Study design}

A retrospective longitudinal study was conducted from 1st Jan 2016 to 30 June 2016 in an out-patient department of a tertiary hospital in Doha, Qatar. This study has been performed in accordance with the ethical standards laid down in the 1964 Declaration of Helsinki and its later amendment.

This study obtained ethical approval from Research Ethics Committee, at Medical Research Center, Hamad Medical Corporation (HMC), Doha, Qatar (IRB No \#15175).

\section{Study population}

This Study was conducted in the out-patient department in general geriatric clinic of a Rumailah hospital in Doha, Qatar. The patients with Type $2 \mathrm{DM}$, around 60 years of age (middle-aged and young old) are included for the study. Non-Type $2 \mathrm{DM}$, less than 50 years of age are excluded from the study.

\section{Sample size}

For $95 \%$ confidence interval and, significance level $\alpha=5 \%, P=90 \%$, $\mathrm{Q}=10 \%$, allowable error $=6 \%$, required sample size was 118 . $\mathrm{P}=$ percentage of Oral hypoglycemic drugs used for the treatment of Type 2 DM. In the pilot study done prior to the original study with 10 patients presented to the out-patient department with Type 2 DM. But we colleted 150 middle-aged and older patients.

\section{Data collection}

The data collected were age, sex, duration of DM, laboratory findings, vital signs, number of all medicines prescribed, number of medicines prescribed by generic name, number of antidiabetic and antihypertensive medicines prescribed, number of essential antidiabetic medicines name, class, route of administration and comorbidities were abstracted.

\section{Statistical analysis}

The gathered data were analyzed using the SPSS v20.0 (Statistical Package for Social Sciences version 20 Inc. USA). Methods for the analysis are Continuous variables analyzing by using student t-test or one-way ANOVA, for skewed continuous data, a non-parametric Mann-Whitney test, and categorical variables compared by using the chi-square test and associations between DM and socio-demographic and clinical indicators were evaluated. ROC analysis was done to find out the cut off for HbAlc level. P-value $<0.05$ was considered to be statistically significant.

\section{Results}

Table 1 shows the demographics, clinical characteristics, comorbidities and laboratory findings in geriatric patients with type 2 DM. From the 150 patients, 80 (53.3\%) were female and remaining 70 (46.7\%) were male and their mean age was 66.9. From the chosen sample, the number of Qatari was 75 (50\%) and 75 belongs to other nationalities. The Comorbidity results show Hypertension was the most common among 108 (72.0\%) patients, followed by Dyslipidemia among $66(44.0 \%)$ and the least common was congestive heart failure with $1(0.7 \%)$ patients. The table also shows that the mean score of Systolic blood pressure (146.9), Diastolic blood pressure (73.8) and Body Mass Index (31.1). The laboratory findings show that the creatinine was high with a mean score of 83 . The Urine Albumin/ Creatinine Ratio of the patients was 3.8. The test on HbA1C level on 146 patients shows that it is $\leq 7.0 \%$ among 54 (37\%) patients and $>7.0 \%$ among $92(63 \%)$ patients. The mean scores 105 patient's Fasting blood sugar level was $7.9 \pm 2.3$.

Table 2 shows the percentage of patients with T2DM on antidiabetic treatment regimens. Under variable treatment regimens, the majority of 118 (78.7\%) patients were using Metformin while the least commonly used was Acarbose $1(0.7 \%)$. For insulin, the most commonly used treatment regimens was Glargine Insulin 28 (18.7\%)) and least commonly used was Human Mixtard Insulin 30/70 by 9 (6.0\%) patients. With regards to Anti-hypertensive, Amlodipine was the most prescribed medication for 67 (44.7\%), followed by Valsartan by $55(36.7 \%)$ patients and Losartan by $11(7.3 \%)$ patients. For Beta Blocker, the medication was as follows, Metoprolol 6 (4.0\%), Atenolol 5 (3.3\%), and Bisoprolol 3 (2.0\%).

Table 3 shows the baseline characteristics of patients with DM on medication (HbA1C target achieved). 
Citation: Nadukkandiyil N, Nadukkandiyil HK, Kunnummal NK, Umminiyattle F, Valappil SA, et al. (2018) A retrospective study of Medication Utilization Pattern and Clinical Outcome in Middle-Aged and Older Patients with Type 2 Diabetes Mellitus in Qatar. J Diabetes Metab 9: 815. doi:10.4172/2155-6156.1000815

Page 3 of 11

\begin{tabular}{|c|c|}
\hline \multicolumn{2}{|l|}{ Age group } \\
\hline $55-64$ & $59(39.3 \%)$ \\
\hline $65-74$ & $72(48 \%)$ \\
\hline$\geq 75$ & $19(12.7 \%)$ \\
\hline \multicolumn{2}{|l|}{ Gender } \\
\hline Females & $80(53.3 \%)$ \\
\hline Males & $70(46.7 \%)$ \\
\hline \multicolumn{2}{|l|}{ Nationality } \\
\hline Qatari & $75(50 \%)$ \\
\hline Duration of DM (years) $(n=51)$ & $14.4 \pm 7.8$ \\
\hline \multicolumn{2}{|l|}{ Co-morbidities } \\
\hline Hypertension & $108(72.0 \%)$ \\
\hline Dyslipidemia & $66(44.0 \%)$ \\
\hline Cerebrovascular accidents & $11(7.3 \%)$ \\
\hline Coronary artery disease $(C A D)$ & $10(6.7 \%)$ \\
\hline Dementia & $7(4.7 \%)$ \\
\hline Chronic kidney (CKD) & $6(4.0 \%)$ \\
\hline Congestive heart failure & $1(0.7 \%)$ \\
\hline \multicolumn{2}{|l|}{ Variables } \\
\hline Aspartate aminotransferase & $21.6 \pm 9.9$ \\
\hline Alanine Aminotransferase & $23.4 \pm 14.9$ \\
\hline Creatinine & $83.0 \pm 36.1$ \\
\hline Urine Albumin/ Creatinine Ratio & $3.8(0.3-350.8)$ \\
\hline HbA1c level $(n=146)$ & $8.1 \pm 1.7$ \\
\hline$\leq 7.0 \%$ & $54(37 \%)$ \\
\hline$>7.0 \%$ & $92(63 \%)$ \\
\hline Fasting blood sugar $(n=105)$ & $7.9 \pm 2.3$ \\
\hline Total cholesterol & $4.2 \pm 1.0$ \\
\hline Low-Density Lipoprotein-LDL & $2.3 \pm 1.1$ \\
\hline Triglycerides-TG & $1.7 \pm 0.8$ \\
\hline Systolic blood pressure & $147.2 \pm 20.3$ \\
\hline Diastolic blood pressure & $74.2 \pm 9.3$ \\
\hline Body Mass Index & $31.1 \pm 6.3$ \\
\hline
\end{tabular}

BMI range was observed at $31.5 \pm 6.8$; Systolic blood pressure of patients with $\mathrm{DM}$ on medication of $\mathrm{HbA1C}>7.0 \%$ at $147.2 \pm 20.2$; Diastolic blood pressure was observed higher in $\mathrm{HbA1C}>7.0 \%$ at 74.2 \pm 9.6; Body Mass Index was higher in $\mathrm{HbAlC}>7.0 \%$ at $31.5 \pm 6.8$ and duration of diabetes was noticed as higher in $11.0 \pm 7.6(\mathrm{HbA1C} \leq$ $7.0 \%)$.

\begin{tabular}{|c|c|c|}
\hline Variables & Values $\mathbf{n}(\%)$ & $95 \% \mathrm{Cl}$ \\
\hline \multicolumn{3}{|l|}{ Anti-diabetics } \\
\hline Metformin & $118(78.7 \%)$ & $(75.4-82.0)$ \\
\hline Gliclazide & $49(32.7 \%)$ & $(28.9-36.5)$ \\
\hline Sitagliptin & $41(27.3 \%)$ & $(23.7-30.9)$ \\
\hline Vildagliptin & $26(17.3 \%)$ & $(14.2-20.4)$ \\
\hline Glimipride & $22(14.7 \%)$ & $(11.8-17.6)$ \\
\hline Glibenclamide & $7(4.7 \%)$ & $(2.9-6.4)$ \\
\hline Glipizide & $6(4.0 \%)$ & $(2.4-5.6)$ \\
\hline Acarbose & $1(0.7 \%)$ & $(0.02-1.4)$ \\
\hline Liraglutide & $8(5.3 \%)$ & $(3.5-7.1)$ \\
\hline \multicolumn{3}{|l|}{ Various Insulins } \\
\hline Glargine Insulin & $28(18.7 \%)$ & $(15.5-21.9)$ \\
\hline Insulin Lispro & $20(13.3 \%)$ & $(10.5-16.1)$ \\
\hline Insulin Aspart & $13(8.7 \%)$ & $(6.4-11)$ \\
\hline Human Mixtard Insulin 30/70 & $9(6.0 \%)$ & $(4.1-7.9)$ \\
\hline \multicolumn{3}{|l|}{ Anti-hypertensive } \\
\hline Amlodipine & 67 (44.7\%) & $(40.6-48.8)$ \\
\hline Valsartan & $55(36.7 \%)$ & $(32.8-40.6)$ \\
\hline Losartan & $11(7.3 \%)$ & $(5.2-9.4)$ \\
\hline \multicolumn{3}{|l|}{ Beta Blocker } \\
\hline Metoprolol & $6(4.0 \%)$ & $(2.4-5.6)$ \\
\hline Atenolol & $5(3.3 \%)$ & $(1.8-4.8)$ \\
\hline Bisoprolol & $3(2.0 \%)$ & $(0.9-3.1)$ \\
\hline
\end{tabular}

Table 2: Percentage of patients on various treatment regimens.

The characteristics Chronic diseases of the patients were noted at higher in $\mathrm{HbAlC}>7.0 \%$ as hypertension was higher among 67 (72.8\%)patients, Cerebrovascular accidents was higher among 6 (6.5\%) patients, Coronary artery disease was 6 (6.5\%), Dyslipidemia was higher in 40 (43.5\%); Chronic kidney disease was higher in 4 (4.3\%). But dementia shown higher among $5(9.3 \%)$ at $\mathrm{HbAlC} \leq 7.0 \%$;

Laboratory findings examined the fasting blood sugar was $8.9 \pm 2.6$; Urine Albumin/ Creatinine Ratio was 4.1(0.8-350.8); High-Density Lipoprotein-cholesterol was $1.2 \pm 0.5$; Total cholesterol was $4.3 \pm 1.1$; Triglycerides was $1.7 \pm 0.8$ at $\mathrm{HbA1C}>7.0 \%$ and slightly high lowdensity lipoprotein-cholesterol was observed as $2.4 \pm 1.1$ at $\mathrm{HbA1C} \leq$ 
Citation: Nadukkandiyil N, Nadukkandiyil HK, Kunnummal NK, Umminiyattle F, Valappil SA, et al. (2018) A retrospective study of Medication Utilization Pattern and Clinical Outcome in Middle-Aged and Older Patients with Type 2 Diabetes Mellitus in Qatar. J Diabetes Metab 9: 815. doi:10.4172/2155-6156.1000815

Page 4 of 11

7.0\%. The findings were not statistically significant related to $\mathrm{HbAlc}$ (Table 4).

Out of the total 146 prescribed antidiabetic treatment, 47 (51.1\%) were Oral hypoglycemic drugs + Insulin which was the most common treatment among $\mathrm{HbA} 1 \mathrm{C}>7.0 \%$, preceding was the Oral hypoglycemic drugs in combination with $32.6 \%$ in $\mathrm{HbAlC}>7.0 \%$. Whereas in $\mathrm{HbA} 1 \mathrm{C} \leq 7.0 \%$, the most common anti-diabetic treatment was Oral hypoglycemic drugs in combination with $48.1 \%$ and the next common treatment was oral hypoglycemic drugs monotherapy with $37.0 \%$.

\begin{tabular}{|c|c|c|c|}
\hline & $\begin{array}{c}\mathrm{HbA} 1 \mathrm{C} \leq 7.0 \% \\
n=54(37 \%)\end{array}$ & $\begin{array}{c}\mathrm{HbA} 1 \mathrm{C}>7.0 \% \\
\mathrm{n}=92(63 \%)\end{array}$ & $P$ value \\
\hline Age (mean $\pm S D$ ) years & $68.2 \pm 5.9$ & $66.1 \pm 5.7$ & 0.03 \\
\hline Females & $30(55.6 \%)$ & $47(51.1 \%)$ & 0.6 \\
\hline Qatari nationals & $29(53.7 \%)$ & $42(45.7 \%)$ & 0.34 \\
\hline Systolic blood pressure & $145.5 \pm 20.2$ & $147.2 \pm 20.2$ & 0.62 \\
\hline Diastolic blood pressure & $73.4 \pm 10.9$ & $74.2 \pm 9.6$ & 0.66 \\
\hline Body mass Index & $30.4 \pm 5.7$ & $31.5 \pm 6.8$ & 0.35 \\
\hline Duration of diabetes & $11.0 \pm 7.6$ & $7.7 \pm 7.0$ & 0.04 \\
\hline \multicolumn{4}{|l|}{ Diseases } \\
\hline Hypertension & $39(72.2 \%)$ & $67(72.8 \%)$ & 0.93 \\
\hline Cerebrovascular accidents & $5(9.3 \%)$ & $6(6.5 \%)$ & 0.54 \\
\hline Coronary artery disease & $3(5.6 \%)$ & $6(6.5 \%)$ & 0.81 \\
\hline Congestive heart failure & $0(0.0 \%)$ & $1(1.1 \%)$ & 0.44 \\
\hline Dementia & $5(9.3 \%)$ & $2(2.2 \%)$ & 0.05 \\
\hline Dyslipidemia & $24(44.4 \%)$ & $40(43.5 \%)$ & 0.91 \\
\hline Chronic kidney disease & $2(3.7 \%)$ & $4(4.3 \%)$ & 0.85 \\
\hline \multicolumn{4}{|l|}{ Laboratory findings } \\
\hline Fasting blood sugar & $6.9 \pm 1.4$ & $8.9 \pm 2.6$ & 0.001 \\
\hline $\begin{array}{l}\text { Urine Albumin/ Creatinine } \\
\text { Ratio }\end{array}$ & $2.7(0.3-19.1)$ & $4.1(0.8-350.8)$ & 0.12 \\
\hline $\begin{array}{l}\text { Low Density Lipoprotein- } \\
\text { cholesterol }\end{array}$ & $2.4 \pm 1.1$ & $2.3 \pm 1.1$ & 0.7 \\
\hline $\begin{array}{l}\text { High Density Lipoprotein- } \\
\text { cholesterol }\end{array}$ & $1.2 \pm 0.3$ & $1.2 \pm 0.5$ & 0.97 \\
\hline Triglycerides & $1.6 \pm 0.9$ & $1.7 \pm 0.8$ & 0.24 \\
\hline Total cholesterol & $4.2 \pm 0.9$ & $4.3 \pm 1.1$ & 0.4 \\
\hline
\end{tabular}

Table 3: Baseline characteristics of patients with DM on medication (HbA1C target achieved).

In Oral hypoglycemic drugs monotherapy, the most commonly utilized drug was Metformin in both HbAlc $>7.0 \%$ and $\mathrm{HbAlc} \leq 7.0 \%$, with $72(78.3 \%)$ and $45(83.3 \%)$ respectively. Gliclazide drug was used more in $\mathrm{HbAlc}>7.0 \%$ with $34(37.0 \%)$ when compared to $\mathrm{HbAlc} \leq$ $7.0 \%$ which was $13(24.1 \%)$.

\begin{tabular}{|c|c|c|c|}
\hline & $\begin{array}{l}\mathrm{HbA} 1 \mathrm{C} \leq 7.0 \% \\
(\mathrm{n}=54)\end{array}$ & $\begin{array}{l}\mathrm{HbA} 1 \mathrm{C}>7.0 \% \\
\quad(\mathrm{n}=92)\end{array}$ & $\begin{array}{c}P \\
\text { value }\end{array}$ \\
\hline \multicolumn{4}{|l|}{ Anti-diabetic treatment } \\
\hline $\begin{array}{l}\text { Oral hypoglycemic drugs } \\
\text { monotherapy }\end{array}$ & $20(37.0 \%)$ & $11(12.0 \%)$ & \multirow{5}{*}{$\begin{array}{l}0.001 \\
\text { for all }\end{array}$} \\
\hline $\begin{array}{l}\text { Oral hypoglycemic drugs in } \\
\text { combination }\end{array}$ & $26(48.1 \%)$ & $30(32.6 \%)$ & \\
\hline $\begin{array}{l}\text { Oral hypoglycemic drugs + } \\
\text { Insulin }\end{array}$ & $5(9.3 \%)$ & $47(51.1 \%)$ & \\
\hline Insulin alone & $2(3.7 \%)$ & $3(3.3 \%)$ & \\
\hline No drug & $1(1.9 \%)$ & $1(1.1 \%)$ & \\
\hline \multicolumn{4}{|c|}{ Oral hypoglycemic drugs monotherapy } \\
\hline Metformin & $45(83.3 \%)$ & $72(78.3 \%)$ & 0.45 \\
\hline Gliclazide & $13(24.1 \%)$ & $34(37.0 \%)$ & 0.1 \\
\hline Sitagliptin & $15(27.8 \%)$ & $24(26.1 \%)$ & 0.82 \\
\hline Vildagliptin & $6(11.1 \%)$ & $19(20.7 \%)$ & 0.14 \\
\hline Glimipride & $5(9.3 \%)$ & $16(17.4 \%)$ & 0.17 \\
\hline Liraglutide & $0(0.0 \%)$ & $8(8.7 \%)$ & 0.02 \\
\hline \multicolumn{4}{|c|}{ Oral hypoglycemic drugs in combination } \\
\hline Metformin + Vildagliptin & $6(11.1 \%)$ & $16(17.4 \%)$ & 0.3 \\
\hline Metformin + Gliclazide & $11(20.4 \%)$ & $25(27.2 \%)$ & 0.35 \\
\hline Metformin + Sitagliptin & $11(20.4 \%)$ & $21(22.8 \%)$ & 0.72 \\
\hline Metformin + Glimipride & $4(7.4 \%)$ & $14(15.2 \%)$ & 0.16 \\
\hline Metformin + Liraglutide & $0(0.0 \%)$ & $6(6.5 \%)$ & 0.05 \\
\hline Metformin + Glargine Insulin & $2(3.7 \%)$ & $18(19.6 \%)$ & 0.007 \\
\hline
\end{tabular}

Table 4: Type $2 \mathrm{DM}$ patients on medication (HbA1C target achieved).

\begin{tabular}{|l|l|l|l|}
\hline & \multicolumn{1}{|c|}{$\begin{array}{c}\text { No HTN } \\
(\mathbf{n}=\mathbf{4 2})\end{array}$} & HTN $(\mathbf{n = 1 0 8 )}$ & P value \\
\hline Age (mean \pm SD) years & $66.5 \pm 5.3$ & $67.1 \pm 6.0$ & 0.55 \\
\hline Males & $18(42.9 \%)$ & $52(48.1 \%)$ & 0.56 \\
\hline HbA1C level & $8.0 \pm 1.8$ & $8.1 \pm 1.7$ & 0.88 \\
\hline Fasting blood sugar & $7.4 \pm 1.9$ & $8.2 \pm 2.4$ & 0.12 \\
\hline $\begin{array}{l}\text { Low Density Lipoprotein- } \\
\text { cholesterol }\end{array}$ & $2.7 \pm 1.3$ & $2.2 \pm 0.9$ & 0.01 \\
\hline $\begin{array}{l}\text { High Density Lipoprotein- } \\
\text { cholesterol }\end{array}$ & $1.1 \pm 0.3$ & $1.2 \pm 0.5$ & 0.52 \\
\hline Triglycerides & $1.7 \pm 0.7$ & $1.6 \pm 0.8$ & 0.61 \\
\hline Total cholesterol & $4.6 \pm 1.2$ & $4.1 \pm 0.9$ & 0.03 \\
\hline
\end{tabular}

Table 5: Baseline characteristics of patients with type 2 DM with HTN.

Other drugs such as Sitagliptin, Vildagliptin, Glimipride, and Liraglutide was utilized more in $\mathrm{HbA} 1 \mathrm{c}>7.0 \%$ whereas when compared 
Citation: Nadukkandiyil N, Nadukkandiyil HK, Kunnummal NK, Umminiyattle F, Valappil SA, et al. (2018) A retrospective study of Medication Utilization Pattern and Clinical Outcome in Middle-Aged and Older Patients with Type 2 Diabetes Mellitus in Qatar. J Diabetes Metab 9: 815. doi:10.4172/2155-6156.1000815

Page 5 of 11

with $\mathrm{HbAlc} \leq 7.0 \%$ these drugs were utilized less frequently. In Oral hypoglycemic drugs combination, the most commonly utilized combinations were Metformin + Gliclazide in $\mathrm{HbA1C}>7.0 \%$ with 25 (27.2\%). In $\mathrm{HbA} 1 \mathrm{C} \leq 7.0 \%$ the most commonly utilized combinations were Metformin + Sitagliptin with $11(20.4 \%)$ and that was equal to Metformin + Gliclazide with 11 (20.4\%) (Table 5).

A major risk factor for cardiovascular diseases in particular with type $2 \mathrm{DM}$ was Hypertension. Hence, on evaluating the presence of hypertension among type $2 \mathrm{DM}$, it was found that most of the male (48.1\%) patients had hypertension with a mean age of $67.1( \pm 6.0)$. On assessing $\mathrm{HbA1C}$ level among patients with and without hypertension; it was found that the levels were having only slight variation among hypertension patients with a mean score $8.1( \pm 1.7)$ and in not having hypertension, the mean score was $8.0( \pm 1.8)$. According to fasting blood sugar, the mean score of hypertension was $8.2( \pm 2.4)$ and with no hypertension, it was 7.4 ( \pm 1.9$)$. By analyzing low-density lipoprotein-cholesterol, no hypertensive had higher mean value 2.7 ( \pm 1.3) whereas they are at the risk of heart diseases and stroke but when compared with mean value of $2.2( \pm 0.9)$ of hypertension it is low. Hence, patients with high levels of low-density lipoproteins are at risk of heart diseases and stroke because lipoproteins carry cholesterol all over the body wherein low-density lipoproteins are also called as highrisk cholesterol making up most of the body's cholesterol. Conversely, in assessing high-density lipoprotein-cholesterol, it was found that there was a slight difference between hypertension and no hypertension was the mean values were $1.2( \pm 0.5)$ and $1.1( \pm 0.3)$. On analyzing the levels of triglycerides it was identified that only small variation in the mean values $1.7( \pm 0.7)$ and $1.6( \pm 0.8)$ among not having hypertension and hypertensive.

Further on evaluating the total cholesterol level it was found that not having hypertension had a higher mean score of $4.6( \pm 1.2)$ when compared with a mean score of hypertension 4.1 ( \pm 0.9$)$ (Figure 1).

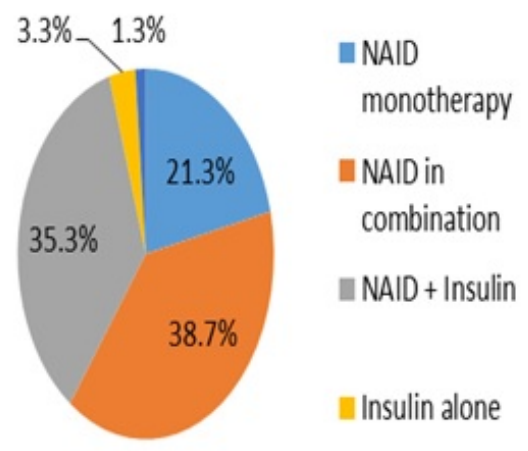

Figure 1: Percentage of antidiabetic treatment among Type 2DM [non-insulin anti-diabetic (NIAD)].

On analyzing the percentage of anti- diabetic treatment among patients with T2DM, it was identified that patients with non-insulin anti-diabetic (NIAD) in combination were higher with $38.7 \%$, followed by NIAD + Insulin with $35.3 \%$ and NIAD monotherapy with $21.3 \%$. The least percentage was $1.3 \%$ with no drug and treatment with no insulin it was 3.3\% (Figure 2).

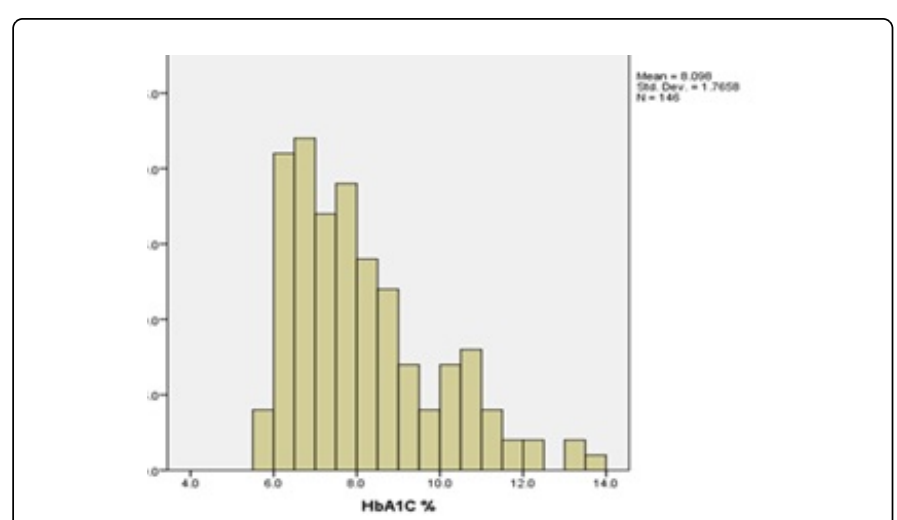

Figure 2: Histogram of observed HemoglobinA1c (HbA1C) values in patients with DM.

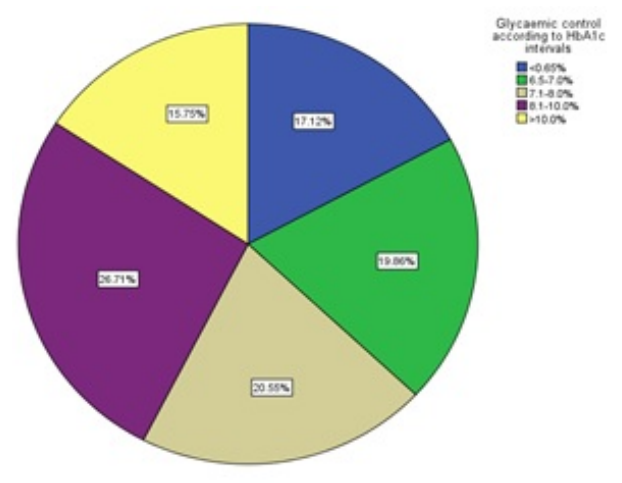

Figure 3: Percentage of patients achieving glycaemic control according to HbAlc intervals.

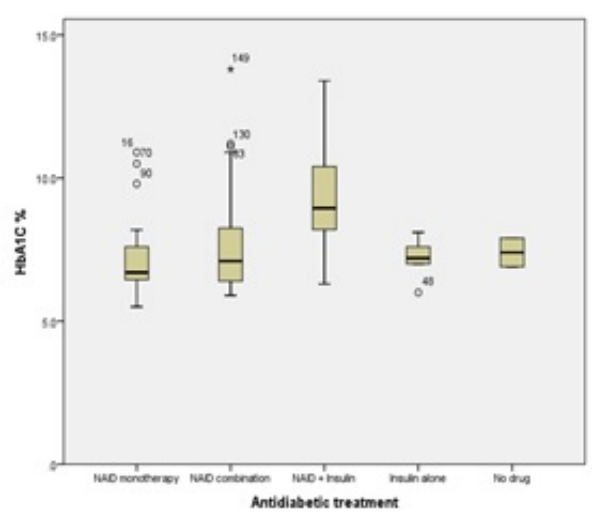

Figure 4: Median HbAlc according to the different antidiabetic treatments $(\mathrm{P}=0.001)$.

It represents the distribution of HbAlc values in patients with DM and achieving glycaemic control (Figure 3 and 4) was observed. A great number of patients cluster around the median of $7.0 \%$, at 28.71 percent of the patients. $20.55 \%$ of patients had $\mathrm{HbAlc}$ values within a range of $6.5-7 \%, 19.86 \%$ had $\mathrm{HbAlc}$ values within a range of below 
Citation: Nadukkandiyil N, Nadukkandiyil HK, Kunnummal NK, Umminiyattle F, Valappil SA, et al. (2018) A retrospective study of Medication Utilization Pattern and Clinical Outcome in Middle-Aged and Older Patients with Type 2 Diabetes Mellitus in Qatar. J Diabetes Metab 9: 815. doi:10.4172/2155-6156.1000815

Page 6 of 11

$6.5 \%$, and $17.12 \%$ had $\mathrm{HbAlc}$ values with the range of $<0.65 \%$ and $15.75 \%$ shows the glycaemic control as per HbAlc intervals (>10\%).

It analyzed the association of different anti-diabetic treatment groups $(\mathrm{P}=0.001)$ with $\mathrm{HbAlc}$. It was noticed the highest of 149 in NIAD combination, i.e., NIAD combination was significantly associated with median $\mathrm{HbAlc} \%$.

Non-insulin antidiabetic drug prescriptions (Sulphonylurea and DPP4i alone or in combination) according to target HbAlc was outlined in Figure 5. The use of a combination of Metformin/ Sitagliptin/ Vildagliptin shows higher non-insulin antidiabetic drug prescriptions as per achieving the target $\mathrm{HbAlc}<7.0 \%$ but it was low in $\mathrm{HbA} 1 \mathrm{c}>7.0 \%$.

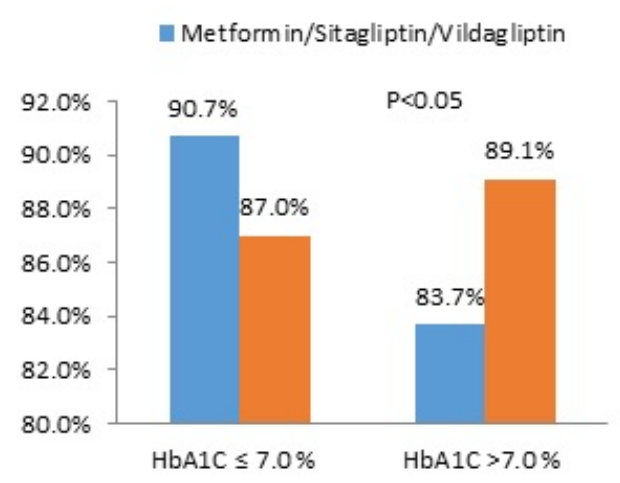

Figure 5: Non-insulin antidiabetic drug prescriptions (Sulphonylurea and DPP4i alone or in combination) according to target $\mathrm{HbA1c}$.

The correlation between age and HbA1c levels $(p=0.03)$ is shown in Figure 6 . The p-value was 0.03 which shows that there was a significant negative correlation between age and HbAlc levels.

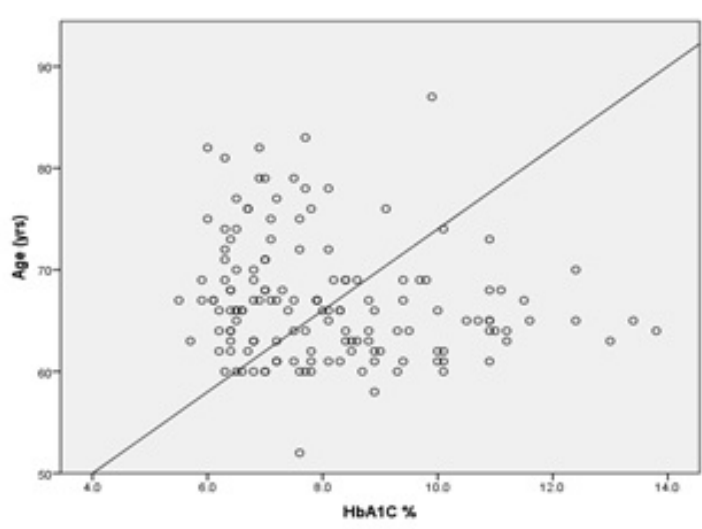

Figure 6: Correlation between age and HbAlc levels $(r=-0.18$; $\mathrm{p}=0.03)$.

The correlation between Fasting blood Sugar (FBS) and HbAlc levels is represented in Figure 7. The p-value is 0.001 which is lower than 0.05 . It shows there is a significant positive correlation between FBS and HbAlc levels.
It shows the correlation between SBP and HbAlc levels. The p-value is 0.98 which is higher than 0.05 . It shows there is no significant correlation between SBP and HbAlc levels.

The study further analyzed the association of different treatment groups as outlined in Figure 8 with HbAlC: The use of insulin, either alone or in combination with NIAD or NIAD alone or combination was used.

Highest of NIAD alone or combination shows higher combination with target $\mathrm{HbAlc} \leq 7 \%$ at $86.8 \%$; NIAD and combination of insulin show higher combination with target $\mathrm{HbAlc}>7 \%$ at $51.6 \%$ and insulin alone treatment expresses less combination with $\mathrm{HbAlc} \leq 7 \%$ at $3.8 \%$ (Figure 9).

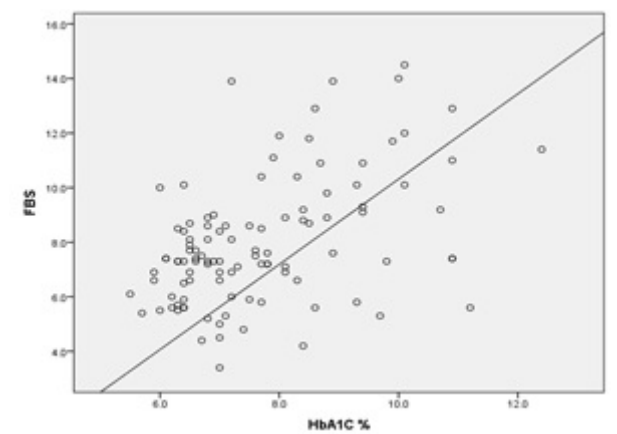

Figure 7: Correlation between FBS and HbAlc levels $(r=0.47$; $\mathrm{p}=0.001$ ).

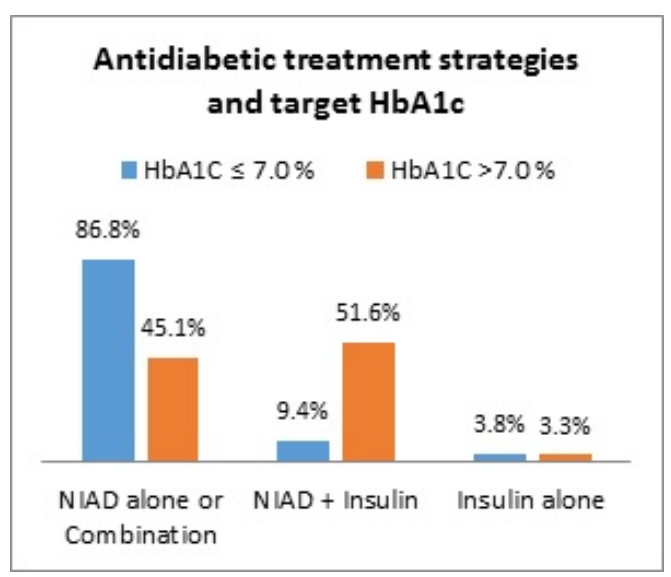

Figure 8: Association of anti-diabetic treatment strategies and target HbA1c. 
Citation: Nadukkandiyil N, Nadukkandiyil HK, Kunnummal NK, Umminiyattle F, Valappil SA, et al. (2018) A retrospective study of Medication Utilization Pattern and Clinical Outcome in Middle-Aged and Older Patients with Type 2 Diabetes Mellitus in Qatar. J Diabetes Metab 9: 815. doi:10.4172/2155-6156.1000815

Page 7 of 11

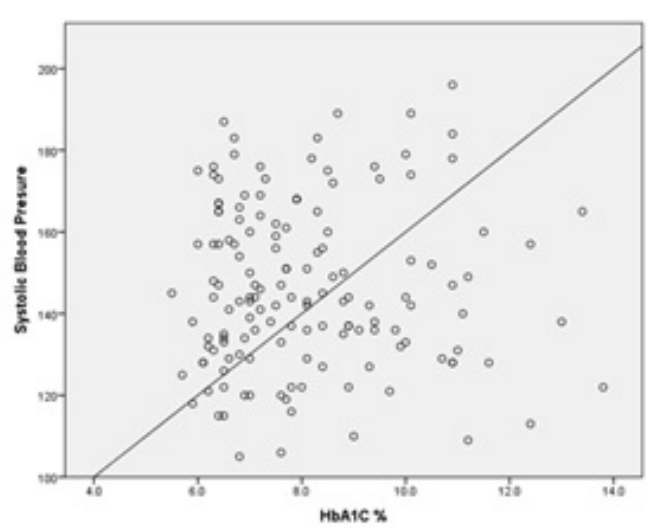

Figure 9: Correlation between SBP and HbA1c levels $(r=-0.002$; $\mathrm{p}=0.98)$.

Table 6 show the comparison of baseline characteristics and antidiabetic treatment of patients with DM based on different age groups. Patients with middle-age were more likely to be prescribed for Metformin as compared to older groups $(\mathrm{p}=0.008)$.

However, the three groups were comparable for demographics, comorbidities and other anti-diabetic medications.

\begin{tabular}{|c|c|c|c|c|c|c|c|c|c|}
\hline & & B & SF & Wald & $d f$ & Sia & Exp & $\begin{array}{r}95 \% \\
\text { EX }\end{array}$ & $\begin{array}{l}\text { C.I.for } \\
\text { (B) }\end{array}$ \\
\hline & & & & & & & & Lower & Upper \\
\hline & Age & 0.158 & 0.069 & 5.167 & 1 & 0.023 & 1.171 & 1.022 & 1.342 \\
\hline & BMI & 0.112 & 0.067 & 2.788 & 1 & 0.095 & 1.118 & 0.981 & 1.275 \\
\hline & FBS & -0.403 & 0.173 & 5.451 & 1 & 0.02 & 0.668 & 0.476 & 0.937 \\
\hline & $\begin{array}{l}\text { OHD } \\
\text { Mono }\end{array}$ & 1.824 & 1.714 & 1.133 & 1 & 0.287 & 6.197 & 0.215 & 178.253 \\
\hline $\begin{array}{c}\text { Step } \\
1 \mathrm{a}\end{array}$ & $\begin{array}{l}\text { OHD } \\
\text { combination }\end{array}$ & -0.339 & 1.59 & 0.046 & 1 & 0.831 & 0.712 & 0.032 & 16.068 \\
\hline & $\mathrm{OHD}$ & -2.172 & 1.672 & 1.688 & 1 & 0.194 & 0.114 & 0.004 & 3.019 \\
\hline & $\begin{array}{l}\text { Insulin Or } \\
\text { alone (1) }\end{array}$ & & & & & & & & \\
\hline & Gender (1) & 0.086 & 0.672 & 0.016 & 1 & 0.899 & 1.089 & 0.292 & 4.065 \\
\hline & Constant & -10.38 & 5.953 & 3.041 & 1 & 0.081 & 0 & & \\
\hline
\end{tabular}

a. Variable(s) entered on step 1: Age, BMI, FBS, OHD_Mono, OHD_combination, OHD_Insulin_Or_alone, Gender.

Table 6: Variables in the Equation.

\begin{tabular}{|c|c|c|c|c|c|c|}
\hline \multicolumn{7}{|c|}{ Model Summary } \\
\hline $\begin{array}{l}\text { Mode } \\
\text { I }\end{array}$ & $R$ & R Square & $\begin{array}{l}\text { Adjusted R } \\
\text { Square }\end{array}$ & $\begin{array}{l}\text { Std. The } \\
\text { Estimate }\end{array}$ & \multicolumn{2}{|c|}{ error of the } \\
\hline 1 & $0.678 a$ & 0.46 & 0.352 & \multicolumn{3}{|l|}{1.2175} \\
\hline \multicolumn{7}{|c|}{ a. Predictors: (Constant), BMI, Antidiabetic_3cat, Age, DM_Duration_Cat, FBS } \\
\hline \multicolumn{7}{|c|}{ ANOVAa } \\
\hline $\begin{array}{l}\text { Mode } \\
1\end{array}$ & & $\begin{array}{l}\text { Sum of } \\
\text { Squares }\end{array}$ & df & $\begin{array}{l}\text { Mean } \\
\text { Square }\end{array}$ & $\mathrm{F}$ & Sig. \\
\hline \multirow[t]{3}{*}{1} & Regression & 31.571 & 5 & 6.314 & 4.26 & $\begin{array}{l}0.006 \\
b\end{array}$ \\
\hline & Residual & 37.057 & 25 & 1.482 & & \\
\hline & Total & 68.628 & 30 & & & \\
\hline
\end{tabular}

a. Dependent Variable: HbA1ClevelPeriodjanDec2015, b. Predictors: (Constant), BMI, Antidiabetic_3cat, Age, DM_Duration_Cat, FBS

\begin{tabular}{|l|l|l|l|l|l|l|}
\hline \multicolumn{2}{|l|}{ Coefficients } \\
\hline Iode
\end{tabular}

a. Dependent Variable: HbA1C level Period Jan Dec 2015

Table 7: Multivariate linear regression.

The above table shows the multivariate linear regression analysis between $\mathrm{HbA1c}$ target level and BMI, antidiabetic medication, age, duration of DM, and FBS. The R-squared value is $0.460, \mathrm{~F}$ value is 4.260 and the $\mathrm{p}$-value is 0.05 .

Since the p-value is higher than 0.05 . After adjusting for relevant covariate, only FBS was found to be an independent predictor of HbA1c target levels.

Figure 10 and ROC analysis yield a cut off value of 7.15 ( ensitivity $=72.4 \%$, specificity $=46.6 \%$ and area under the curve $=0.055$ ). 
Citation: Nadukkandiyil N, Nadukkandiyil HK, Kunnummal NK, Umminiyattle F, Valappil SA, et al. (2018) A retrospective study of Medication Utilization Pattern and Clinical Outcome in Middle-Aged and Older Patients with Type 2 Diabetes Mellitus in Qatar. J Diabetes Metab 9: 815. doi:10.4172/2155-6156.1000815

Page 8 of 11

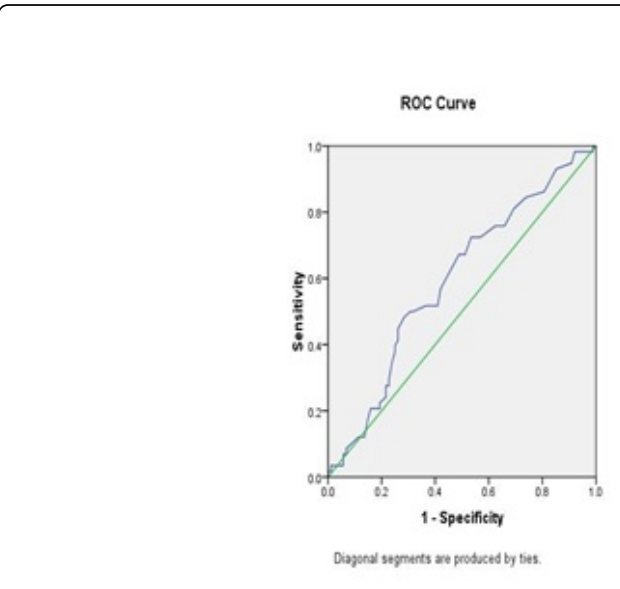

Figure 10: ROC curve of HbAlc for 50-64 years.

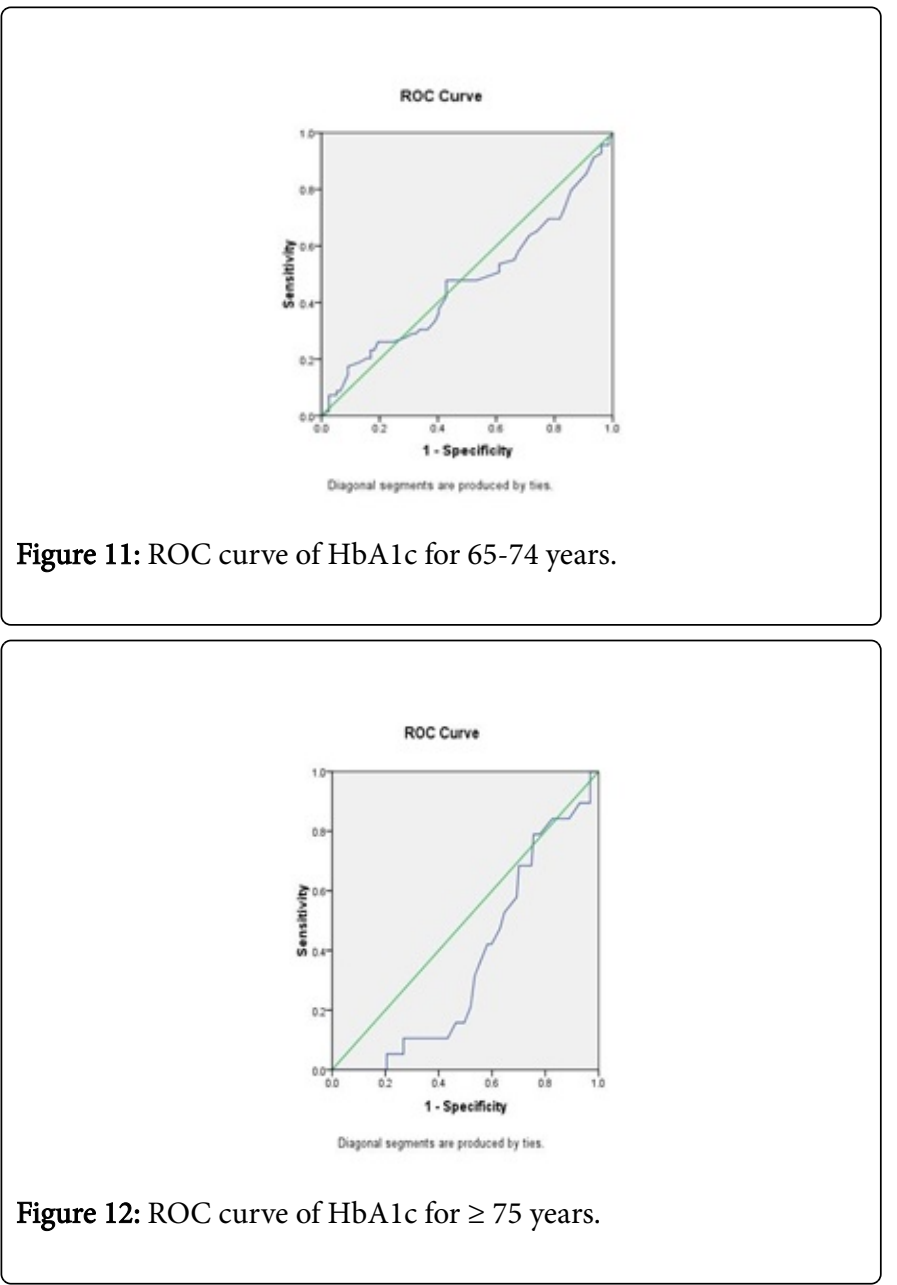

Figure 11 and ROC analysis yield a cut off value of 7.75 (sensitivity $=47.8 \%$, specificity $=51.9 \%$ and area under the curve $=0.471$, $\mathrm{p}=0.547)$.

Figure 12 and ROC analysis yield a cut off value of 7.45 (sensitivity $=42.1 \%$, specificity $=41.7 \%$ and area under the curve $=0.365$, $\mathrm{p}=0.058)$.

\begin{tabular}{|c|c|c|c|}
\hline & $\mathrm{HbA} 1 \mathrm{C} \leq 7.0 \%$ & $\mathrm{HbA} 1 \mathrm{C}>7.0 \%$ & $P$ value \\
\hline Age group 55-64 & $(n=16)$ & $(n=42)$ & \\
\hline \multicolumn{4}{|l|}{ Anti-diabetic treatment } \\
\hline $\begin{array}{l}\text { Oral hypoglycemic drugs } \\
\text { monotherapy }\end{array}$ & $6(37.5 \%)$ & $2(4.8 \%)$ & \multirow{6}{*}{$\begin{array}{l}0.001 \text { for } \\
\text { all }\end{array}$} \\
\hline $\begin{array}{l}\text { Oral hypoglycemic drugs in } \\
\text { combination }\end{array}$ & $9(56.2 \%)$ & $16(38.1 \%)$ & \\
\hline $\begin{array}{l}\text { Oral hypoglycemic drugs + } \\
\text { Insulin }\end{array}$ & $1(6.2 \%)$ & $23(54.8 \%)$ & \\
\hline Insulin alone & $0(0 \%)$ & $1(2.4 \%)$ & \\
\hline No drug & $0(0 \%)$ & $0(0 \%)$ & \\
\hline Age group $65-74$ & $(n=29)$ & $(n=40)$ & \\
\hline \multicolumn{4}{|l|}{ Anti-diabetic treatment } \\
\hline $\begin{array}{l}\text { Oral hypoglycemic drugs } \\
\text { monotherapy }\end{array}$ & $11(37.9 \%)$ & $6(15.0 \%)$ & \multirow{6}{*}{$\begin{array}{l}0.005 \text { for } \\
\text { all }\end{array}$} \\
\hline $\begin{array}{l}\text { Oral hypoglycemic drugs in } \\
\text { combination }\end{array}$ & $13(44.8 \%)$ & $10(25 \%)$ & \\
\hline $\begin{array}{l}\text { Oral hypoglycemic drugs + } \\
\text { Insulin }\end{array}$ & $3(10.3 \%)$ & $22(55 \%)$ & \\
\hline Insulin alone & $1(3.4 \%)$ & $1(2.5 \%)$ & \\
\hline No drug & $1(3.4 \%)$ & $1(2.5 \%)$ & \\
\hline Age group $\geq 75$ & $(n=9)$ & $(n=10)$ & \\
\hline \multicolumn{4}{|l|}{ Anti-diabetic treatment } \\
\hline $\begin{array}{l}\text { Oral hypoglycemic drugs } \\
\text { monotherapy }\end{array}$ & $3(33.3 \%)$ & $3(33 \%)$ & \multirow{5}{*}{$\begin{array}{l}0.963 \text { for } \\
\text { all }\end{array}$} \\
\hline $\begin{array}{l}\text { Oral hypoglycemic drugs in } \\
\text { combination }\end{array}$ & $4(44.4 \%)$ & $4(40 \%)$ & \\
\hline $\begin{array}{l}\text { Oral hypoglycemic drugs + } \\
\text { Insulin }\end{array}$ & $1(11.1 \%)$ & $2(20 \%)$ & \\
\hline Insulin alone & $1(11.1 \%)$ & $1(10 \%)$ & \\
\hline No drug & $0(0 \%)$ & $0(0 \%)$ & \\
\hline
\end{tabular}

Table 8: Age group wise comparison of Type 2 DM patients on medication (HbA1C target achieved).

Table 8 shows that monotherapy was found to be most effective in attaining the target $\mathrm{HbAlc}$ in middle aged and elderly population.

The insulin-based therapies were not effective in all age group to attain better glycemic control compared to oral antidiabetic drugs.

When anti-diabetes medicines consumption was determined with respect to age, it was found that diabetes patients aged 65-74 and $\geq 75$ years had significantly higher consumption of Oral hypoglycemic drugs monotherapy compared to 55-64 years.

\section{Discussion}

This study aimed to evaluate the drug utilization pattern in geriatric Type-2 DM young older patients in an outpatient setting in Rumailah 
Citation: Nadukkandiyil N, Nadukkandiyil HK, Kunnummal NK, Umminiyattle F, Valappil SA, et al. (2018) A retrospective study of Medication Utilization Pattern and Clinical Outcome in Middle-Aged and Older Patients with Type 2 Diabetes Mellitus in Qatar. J Diabetes Metab 9: 815. doi:10.4172/2155-6156.1000815

Page 9 of 11

Hospital. All patients were under the routine care of endo-geriatrics so that the data have to be interpreted as reflecting specialist care.

In order to examine the Type 2 DM patients on medication, study findings show that combination anti-diabetic therapy was more used than monotherapy. In Oral hypoglycemic drugs monotherapy, the most commonly utilized drug was Metformin in both $\mathrm{HbA1C}>7.0 \%$ and $\mathrm{HbA} 1 \mathrm{C} \leq 7.0 \%$, in Oral hypoglycemic drugs combination, the most commonly utilized combinations was Metformin + Gliclazide in $\mathrm{HbA} 1 \mathrm{C}>7.0 \%$ and in $\mathrm{HbA} 1 \mathrm{C} \leq 7.0 \%$, the most commonly utilized combinations were Metformin + Sitagliptin. This was in line with the previous study findings $[7,8]$. From this view, it is important to know that 20 percent of the cohort had HbAlc which is less than $6.5 \%$ ( $48 \mathrm{mmol} / \mathrm{mol}$ ), which could be suggested as either poor health status or overtreatment with a high risk of hypoglycemia [9]. Since the result did not have a significant difference when intensive was associated with the conventional glycaemic control for every causes and mortality which results in lower risk of microvascular complication along with kidney diseases among intensively treated patients with interventional trials $[10,11]$. If there is a presence of renal anemia then HbAlc levels might be lower due to the short lifespan of erythrocytes [12].

Indeed, the study found a slight but significant positive correlation between age and HbAlc and FBS and HbAlc levels. But when hemoglobin values of the patients were analyzed it was found that majority of the patients were under normal range and it is noted as there is no difference in the mean hemoglobin concentrations among patients with $\mathrm{HbA1c}$ values below or above the average. Moreover hemoglobin but not $\mathrm{HbAlc}$ is associated positively with eGFR identified through the findings of [13].

Under variable treatment regimens, majority of 118 (78.7\%) patients were using Metformin; for insulin, the most commonly used treatment regimen is Glargine Insulin 28(18.7\%); with regards to antihypertensive, calcium channel blocker, Amlodipine is the most prescribed medication for patients followed by angiotensin receptor blocker, Valsartan and among Beta Blocker, the medication is Metoprolol 6 (4.0\%). It should be noted that there is an ongoing debate about whether the current thresholds for metformin use as suggested by guidelines may be too restrictive [14].

It is noticed the highest of 149 in NIAD combination, i.e NIAD combination was significantly associated with a median $\mathrm{HbAlc}$ percentage. The use of a combination of Metformin/Sitagliptin or Vildagliptin shows higher non-insulin antidiabetic drug (NIAD) prescriptions as per the target $\mathrm{HbAlc}<7.0 \%$. Treatment with insulin was related to increases in $\mathrm{HbAlc}(8.3 \%$ contrasted with $7.7 \%$ towards oral combination group), increased mortality (HR 1.49), increased likelihood of the major large vessel disease event [15]. Additional retrospective study of Type-2 DM from Germany, were patients were recommended with sulfonylurea or insulin, a combination of insulin along with any oral anti-diabetic drugs, a combination of metformin along with sulfonylurea was less likely to attain an intensive $\mathrm{HbAlc}$ target [16]. The quality of treatment is better or even comparable than in large cohort studies of patients with Type-2DM in Germany which has identified mean values of $\mathrm{HbAlc}$ of 7.0 and $7.2 \%[17,18]$. According to guidelines recommended by Germany, an $\mathrm{HbAlc}$ between $6.5 \%$ and $7.5 \%(48-58 \mathrm{mmol} / \mathrm{mol})$ for every patient with diabetes associated with kidney disease [8] and our cohort was met with $45 \%$ with this criteria. A recent guideline recommendation by U.S. National Kidney Foundation's Kidney Disease Outcome Initiative (K/DOQI) has recommended a target $\mathrm{HbA1C}$ of $~ 7.0 \%$ for preventing or delaying the progress of microvascular complications of DM [7].
Hence according to these guidelines many patients were treated. Various studies have also identified that good metabolic control could be attained in patients with DM. Highest of NIAD alone or combination shows higher combination with target $\mathrm{HbAlc} \leq 7 \%$. The cut off value of HbA1c may vary from older to oldest. Another significant finding of the study is that patterns of Anti-diabetic treatment might differ from general diabetes population and completely highly variable. Overall, moderately more than 50 percent were treated using insulin-based therapies. In Germany, a general Type-2DM population with insulin-based therapy was around $31 \%$ wherein $20 \%$ is lower than in the patient presently analysed [19]. Around $40 \%$ of the patients were treated only with insulin which is particularly higher when compared with general DM cohorts containing along with German cohorts where insulin monotherapy is treated only for $10-20 \%[16,18,20]$. Oral glucose-lowering medication (with or without insulin) treatment was only among one-third of the patients. In the General diabetes population of Germany, patients who receive any oral antidiabetic medication were at 60 to $70 \%$ of the patients [17-19]. Around one-quarter of the cohort, patients were treated with oral antidiabetic agents alone when compared to $75 \%$ of general diabetes cohorts $[18,21]$.

With various levels of metabolic control, diverse treatments were associated. Use of insulin alone or in combination with oral antidiabetic drugs was supplemented with 4 to approximately 6 times higher probability of having $\mathrm{HbAlc}$ values $>7.0 \%$ (53 $\mathrm{mmol} / \mathrm{mol})$. In the same way, usage of oral glucose-lowering drugs alone such as glinides, metformin, DPP-4 inhibitors, or combination of metformin along with DPP-4 inhibitors was not related along with such prospect apart from sulfonylureas. From the observation of the study prevents to depict conclusions over effect and cause while identifying these modifications in metabolic control in patients who are under various therapies and numerous factors might take place. Therefore patients with difficulty in treating diabetes were exchanged and treated with insulin or sulfonylureas, describing at least a part higher with $\mathrm{HbAlc}$ levels in these patients. Moreover, patients with higher HbAlc targets might be selected intentionally in certain patients. When this recommendation is implemented it might explain higher HbAlc levels in certain patients, improbable it might apply for the majority of the insulin-treated patients, provided in younger age there was no difference in eGFR but the only slight high rate was predominant in CVD. According to ADA and European Association for the Study of Diabetes specified that England National Clinical Guideline for Management in Primary and Secondary Care from NICE (National Institute for Health and Care Excellence) [22] is more evidence-based, usually permitting metformin use down to an eGFR of $30 \mathrm{~mL} / \mathrm{min} /$ $1.73 \mathrm{~m} 2$, with decrease dose advised at $45 \mathrm{~mL} / \mathrm{min} / 1.73 \mathrm{~m} 2$ [14,22,23]. Hence the European guideline from 2009 has provoked the German doctors for prescribing metformin in spite of an eGFR of below $60 \mathrm{~mL} / \mathrm{min} / 1.73 \mathrm{~m} 2$. Based on the functional status from the study findings, diabetes care has to be addressed through framing national guidelines for overcome hypertension, Dyslipidemia, Coronary artery disease, Cerebrovascular accidents, Congestive heart failure, Diastolic blood pressure, Systolic blood pressure etc.

There are certain limitations of this study apart from observational nature. There is a lack of information on medication history and treatment duration, which might provide a better understanding for reasons of patients with particular therapies. This study couldn't classify older patient's disease complexities and HbAlc level with respect to frailty Index. The backbone of the study is its size and the assessment of various types of anti-diabetic medication. Information 
Citation: Nadukkandiyil N, Nadukkandiyil HK, Kunnummal NK, Umminiyattle F, Valappil SA, et al. (2018) A retrospective study of Medication Utilization Pattern and Clinical Outcome in Middle-Aged and Older Patients with Type 2 Diabetes Mellitus in Qatar. J Diabetes Metab 9: 815. doi:10.4172/2155-6156.1000815

Page 10 of 11

was gathered directly from the patient's e-record, perhaps to overcome certain uncertainties of implementation rationality of prescription orders in patients when treated with more than one doctor. In a central lab utilizing identical methodology, all HbAlc values were determined. However, this study provides the baseline information to the researchers regarding the drug utilization pattern among a cohort of outpatient's older in the Doha province of Qatar.

\section{Conclusion}

Drug utilization pattern was different according to age group. Monotherapy was found to be most effective in attaining the target $\mathrm{HbAlc}$ in middle aged and young older population. Metformin, Gliclazide, and Sitagliptin were the most predominantly prescribed and consumed anti-diabetes combination medicines. The insulinbased therapies alone were scarce in all age group to attain better glycemic control compared to oral anti-diabetic drugs. Our data suggest that standard treatment guideline was followed properly among older diabetic population in Qatar.

\section{Acknowledgment}

We thank all physicians and out-patient nurses specially, Mrs. Vimala and Mrs. Rhea from the geriatric department for their care and contribution. We are grateful to Mr. Brijesh Sathian, Ph.D \& Mr. Mohammed Asim, Ph.D for their statistical analysis and technical support respectively. All the authors have read and approved the manuscript with no conflict of interest and no financial issues to disclose.

\section{Author Contribution}

NN: study design, Proposal preparation, data review and manuscript writing; HA: study design and manuscript drafting, final review; HS: study design and manuscript editing; SV: study design, data analyzing; NK: manuscript drafting; MR: study design and manuscript editing; FU: manuscript drafting and proofreading; MBR: Proposal preparation, data review; MO: study design and manuscript editing; MA: Datasheet preparation, manuscript drafting; AA: study design, data analyzing; AB: Proposal preparation, data review; ES: study design, data analyzing.

\section{Declaration}

We declare that this manuscript is original, has not been published before and is not currently being considered for publication elsewhere. We know of no conflicts of interest associated with this publication, and there has been no significant financial support for this work that could have influenced the outcome.

\section{References}

1. Kahn CR, Weir GC, King GL, Jacobson AM, Moses AC, et al. (2004) Joslin's Diabetes Mellitus. Philadelphia, Pennsylvania, United States: Lippincott Williams and Wilkins.

2. WHO (2017) Disease Burden and Mortality Estimates. Geneva, Switzerland.

3. World Health Organization (2016) Global Report on Diabetes. France.

4. International Diabetes Federation (2017) IDF Diabetes Atlas. Brussels, Belgium.

5. Nathan DM, Buse JB, Davidson MB, Ferrannini E, Holman RR, et al. (2009) Medical Management of Hyperglycemia in Type 2 Diabetes: A
Consensus Algorithm for the Initiation and Adjustment of Therapy: A consensus statement of the American Diabetes Association and the European Association for the Study of Diabetes. Diabetes Care 32: 193-203.

6. Bener A, Zirie M, Janahi IM, Al-Hamaq AOAA, et al. (2009) Prevalence of diagnosed and undiagnosed diabetes mellitus and its risk factors in a population-based study of Qatar. Diabetes Res Clin Pract 84: 99-106.

7. National Kidney Foundation (2012) KDOQI Clinical Practice Guideline for Diabetes and CKD: 2012 Update. Am J Kidney Dis 60: 850-886.

8. Arztebl D (2011) National Care Guideline Published Kidney Disease in Diabetes in Adulthood.

9. Zoungas S, Patel A, Chalmers J, de Galan BE, Li Q, et al. (2010) Severe Hypoglycemia and Risks of Vascular Events and Death. N Engl J Med 363: 1410-1418.

10. Hemmingsen B, Lund SS, Gluud C, Vaag A, Almdal TP, et al. (2013) Targeting intensive glycaemic control versus targeting conventional glycaemic control for type 2 diabetes mellitus. Cochrane Database Syst Rev 11: CD008143.

11. Perkovic V, Heerspink HL, Chalmers J, Woodward M, Jun M, et al. (2013) Intensive glucose control improves kidney outcomes in patients with type 2 diabetes. Kidney Int 83: 517-523.

12. Inaba M, Okuno S, Kumeda Y, Yamada S, Imanishi Y, et al. (2007) Glycated Albumin Is a Better Glycemic Indicator than Glycated Hemoglobin Values in Hemodialysis Patients with Diabetes: Effect of Anemia and Erythropoietin Injection. J Am Soc Nephrol 18: 896-903.

13. Wolf G, Muller N, Hunger-Battefeld W, Kloos C, Muller UA (2008) Hemoglobin Concentrations Are Closely Linked to Renal Function in Patients with Type 1 or 2 Diabetes Mellitus. Kidney Blood Press Res 31: 313-321.

14. Lu WR, Defilippi J, Braun A (2013) Unleash metformin: reconsideration of the contraindication in patients with renal impairment. Ann Pharmacother 47: 1488-1497.

15. Currie CJ, Peters JR, Tynan A, Evans M, Heine RJ, et al. (2010) Survival as a function of $\mathrm{HbAlc}$ in people with type 2 diabetes: a retrospective cohort study. Lancet 375: 481-489.

16. Yurgin N, Secnik K, Lage MJ (2007) Antidiabetic prescriptions and glycemic control in German patients with type 2 diabetes mellitus: A retrospective database study. Clin Ther 29: 316-325.

17. Ott P, Benke I, Stelzer J, Köhler C, Hanefeld M (2009) Diabetes in Germany"(DIG) study. A prospective 4-year-follow-up study on the quality of treatment for type 2 diabetes in daily practice. Dtsch Med Wochenschr 134: 291-297.

18. Stone MA, Charpentier G, Doggen K, Kuss O, Lindblad U, et al. (2013) Quality of Care of People With Type 2 Diabetes in Eight European Countries. Diabetes Care 36: 2628-2638.

19. Müller N, Heller T, Freitag MH, Gerste B, Haupt CM, et al. (2015) Healthcare utilization of people with Type 2 diabetes in Germany: an analysis based on health insurance data. Diabet Med 32: 951-957.

20. Rafaniello C, Arcoraci V, Ferrajolo C, Sportiello L, Sullo MG, et al. (2015) Trends in the prescription of antidiabetic medications from 2009 to 2012 in a general practice of Southern Italy: A population-based study. Diabetes Res Clin Pract 108: 157-163.

21. Baviera M, Monesi L, Marzona I, Avanzini F, Monesi G, et al. (2011) Trends in drug prescriptions to diabetic patients from 2000 to 2008 in Italy's Lombardy Region: A large population-based study. Diabetes Res Clin Pract 93: 123-130.

22. Royal College of Physicians (2008) Type 2 Diabetes: National Clinical Guideline for Management in Primary and Secondary Care (Update). London, United Kingdom: Royal College of Physicians.

23. Inzucchi SE, Bergenstal RM, Buse JB, Diamant M, Ferrannini E, et al. (2012) Management of Hyperglycemia in Type 2 Diabetes: A PatientCentered Approach: Position Statement of the American Diabetes Association (ADA) and the European Association for the Study of Diabetes (EASD). Diabetes Care 35: 1364-1379. 